\title{
Clinic letters revisited
}

\author{
Martin R Turner, ${ }^{\oplus 1}$ Phillip E M Smith²
}

${ }^{1}$ Nuffield Department of Clinical Neurosciences, Oxford University, Oxford, UK ${ }^{2}$ University Hospital of Wales, Cardiff, UK

\section{Correspondence to} Professor Martin R Turner, Nuffield Department of Clinical Neurosciences, Oxford University, Oxford OX1 2JD, UK martin.turner@ndcn.ox.ac.uk

Accepted 25 May 2019

\section{Check for updates}

(c) Author(s) (or their employer(s)) 2019. No commercial re-use. See rights and permissions. Published by BMJ.

To cite: Turner MR Smith PEM. Pract Neurol Epub ahead of print: [please include Day Month Year]. doi:10.1136/ practneurol-2019-002287
Seasoned readers of Practical Neurology may recall Richard Davenport's treatise on the practicalities of the clinic letter. ${ }^{1}$ One of the few negatives of the increasing move from paper to digital records is that it is no longer easy to read old letters, sometimes going back many decades. Beyond the nostalgic sight of 'carbon copies' of classic typewriter print on wafer-thin paper, we are reminded of the dramatic changes in language and tone of the clinic letter. Copying correspondence to patients has been a major force in improving the quality of letters. Knowing that the patient will read the letter provides a strong incentivise for accurate, clear and polite accounts of consultations. $^{2}$

Yet, parts of contemporary clinic letters still hark back to a bygone age. For example, the opening phrase 'Thank you for referring this pleasant woman...' includes both the value judgement that the patient is pleasant, and thanks for having made the referral. Adjectives describing the patient are redundant unless they have clinical value, and may actually be challenging to articulate even if they convey potentially significant information, for example, 'unkempt' or 'obese'. Doctors often see people whom they may not personally like, but rightly this has no bearing on the consultation. It would be disingenuous to suggest that 'pleasant' conveys anything of clinical value when few of us, if any, would write 'unpleasant', 'repulsive' or 'irritating'. While the letter writer's intention might well be to set a polite and friendly tone, we suggest this could equally be interpreted by the layperson as evidence of professional entitlement, an assertion of hierarchy and wide of the goal of shared decision-making.

Why do so many letters still offer thanks for the referral when the UK's National Health Service (NHS) model of care has an enshrined contract for specialists to see referrals from primary care? A cynic might note that, while the personal income of an NHS neurologist has not (since 1948) depended on a continued pattern of personal referral from primary care, this is different in fee-for-service models of healthcare. Courtesy facilitates business of all sorts, and so thanking the referrer might, again, be justified as a way to set a polite tone. Yet, how often has the response to a difficult email started, 'Thank you', when no thanks were intended? The doctor-centred opening, 'It was my pleasure to meet Mrs Jones...' is also worth avoiding. It may not be comforting to the patient to infer that the discussion of their illness had somehow given the doctor pleasure. A final phrase we offer for reflection on is the reference to 'your patient' in letters to the general practitioner (GP). The implication might be that the neurologist disowns them, when we are surely part of a wider healthcare team?

Why does this stereotyped behaviour persist? It seems likely that dictation habits are handed down letter by letter, and by word of mouth. Trainees read their trainers' letters and repeat the formulations they see. Perhaps a rethink is in order. Rather than thanking the GP for referring their patient, pleasant or otherwise, a factual approach could be tried: 'I reviewed Ms Jones in the neurology clinic today'.

Contributors All the authors contributed equally to the manuscript.

Funding The authors have not declared a specific grant for this research from any funding agency in the public, commercial or not-forprofit sectors.

Competing interests PEMS is co-editor of Practical Neurology.

Patient consent for publication Not required. Provenance and peer review Commissioned; externally peer reviewed by Richard Davenport, Edinburgh, UK and Rhys Thomas, Newcastle, UK.

\section{REFERENCES}

1 Davenport RJ. Write a clinical letter. Pract Neurol 2011;11:85-90.

2 Smith PEM. Letters to patients: sending the right message. BMJ 2002;324:685. 